\title{
Economic Impacts of an Electric Vehicle Society in Toyohashi City, Japan-A CGE Modelling Approach
}

\author{
${ }^{1}$ Yuzuru Miyata, ${ }^{2}$ Hiroyuki Shibusawa, ${ }^{3}$ Shamsunnahar Khanam \\ ${ }^{1,2}$ Graduate School of Architecture and Civil Engineering, Toyohashi University of Technology \\ ${ }^{3}$ Graduate School of Environmental and Life Science, Toyohashi University of Technology
}

\begin{abstract}
In this paper we explore economic impact of promotion and realization of an electric vehicle society (EVS). More concretely, this paper emphasizes on a CGE-modelling approach to evaluate the following issues: entire economic impacts of subsidies for promotion of an EVS, the possibility of carbon dioxide $\left(\mathrm{CO}_{2}\right)$ emissions and prices reduction, industrial structure change towards an EVS, and model shift occurs towards an EVS.

Our simulation results demonstrate that after applying $20 \%$ subsidies to five industries, such as electric vehicles (EVs) manufacturing and transhipment, solar, cogeneration, and other transhipment the total industrial output and city GDP increase. A large growth rate is found in industries where subsidies are introduced alone with non-ferrous metal industry. However, it is motivating that decreasing proportions are found in oil, coal product, mining, heat supply and gasoline vehicles $(G V s)$ transhipment industries.

Moreover, all the commodity prices decrease though in industries where subsidies are presented prices shrink appreciably. Hence, Toyohashi City's economy shows a direction where the demand for conventional vehicles and energy use are decreased, conversely, the demand for EVs and renewable energy are increased that displays different lifestyles from the current.

Thus, introducing $20 \%$ subsidies to EVs manufacturing and transhipment, solar, cogeneration, and other transhipment can really represent a realistic alternative society to EVS, both in terms of economic development and $\mathrm{CO}_{2}$ emissions reduction. In this study therefore it is clear that model shift occurs to EVS, and thus we suggest for promotion of new industrial structure to introduce an EVS in Toyohashi city, Japan. The proposed model even can be expanded to the other cities in Japan and other countries in the world which are similar to this area.
\end{abstract}

Keywords: CGE model, electric vehicle society, electric vehicle, Toyohashi City, Japan

\section{Introduction}

Recently $\mathrm{CO}_{2}$, which mostly forms the largest and growing fraction of greenhouse gas (GHG) emission from transportation sector, presents a major challenge to global climate change mitigation efforts [1]. Worldwide transportation ranks second after electric power as the largest source of emissions, contributing about $20 \%$ of the total in recent trends and future projections [6].

In the case of Japan, similar to the world trend transportation, the country's transportation sector accounts for more than one-fifth of $\mathrm{CO}_{2}$ emission [7]. Especially, emissions generated from passenger and freight cars dominate $90 \%$ of the sector [8], while personal vehicles alone contribute $50 \%$ of transportation emissions in Japan [9]. In addition, it is expected that $\mathrm{CO}_{2}$ emission will be increasing because of expending personal vehicle fleets, particularly in the sub-urban areas like Toyohashi City in Japan.

Thus it has become imperative to introduce a new society based on environmental friendly transportation and renewable energy sources that does not negatively affect the environment. In this study, we aim to introduce an EVS hope to shift demand to EVs and solar energy to reduce $\mathrm{CO}_{2}$ emissions. The study of EVS has been a considerably unexplored field in environmental economics despite the fact of potentially attractive and important theme though there have been little attempts for this topic in environmental economics.

For example, it would be significantly worth to examine how the economic impact of both production and policy implementation for promotion and realization of an EVS. From this point, previously we have applied a CGE model to investigate the economic impacts of EVs production. However, promotion of an EVS not only depends on EVs production, it is required to acquaint with new industries like EVs transhipment as small mileage is the main problem of EVs. It is expected that the spread of EVs would greatly reduce the $\mathrm{CO}_{2}$ emission, however it only depends on internalizing electricity generated from renewable sources of energy like solar. Thus, it is also imperative to consider industries like solar energy generation to introduce an EVS. Moreover, 
Economic Impacts of an Electric Vehicle Society in Toyohashi City, Japan-A CGE

cogeneration is also important to shift the demand to renewable energies from the conventional. Beside, beforehand, we did not consider subsidies, but subsidies may be required to overcome the initial price difference of the new industrial productions.

Taking these backgrounds into account, this article aims to apply a CGE model similar to author's previous study concerning this field [5] to evaluate the possibility and economic impacts of an EVS taking Toyohashi City, Japan as a study region. More concretely, this paper emphasizes a CGE-modelling approach to evaluate the following contents: entire impacts of subsidies for promotion of an EVS, the possibility of $\mathrm{CO}_{2}$ emissions and prices reduction, model shift occurs towards an EVS, industrial structure change towards an EVS.

Toyohashi City is considered as a study region for three reasons: (1) the number of vehicles in the city is increasing rapidly, thus, $\mathrm{CO}_{2}$ emission is seen as an increasing trend, (2) the city has many motor vehicle manufacturers that include the Toyota Motor Company, which is one of the world's largest automobile manufacturers by production, and (3) this city is potential to generate solar energy.

The rest of the paper is organized as follows. In Section 2, the study area and method of the study are described. Section 3 explains the assumptions of the model and behaviours of the economic agents. In Section 4, simulation cases are given, whereas Section 5 presents the results of the simulation. Finally, Section 6 summarizes the conclusion.

\subsection{Study area}

\section{Study Area And Method Of The Study}

Toyohashi City (see Figure 1) is located in the central part of Japan and falls in the prefectural boundary of Aichi. The Pacific Ocean is in the south of the city and the city opens onto Mikawa Bay in the west. Mikawa Port is a major port for worldwide trade, and its presence has made Toyohashi an important city as the biggest import and export hub in Japan for automobile in volume term. The area and population size of the city at founding in 1906 was 19.69 square kilometres and 9,900 persons [10]. At present the size of the city is 261.35 square kilometres with population of 381,977 (density stands at 1462 persons per square kilometre) [11]. Attractive economic activity, especially heavy industries and a large scale sea-port, is attracting migration to the city and data of Statistics Bureau, Japan provides that 10, 749 persons migrated to Toyohashi in 2008, 9,779 persons in 2009, and 8,577 persons in 2010. As a result, the city is experiencing vertical expansion as the land area is remaining unchanged since 1960 [11]. There are many motor vehicle manufacturers in Toyohashi City, including Toyota Motor Company (one of the world's largest automobile manufactures by production), Mitsubishi and Suzuki Motors.

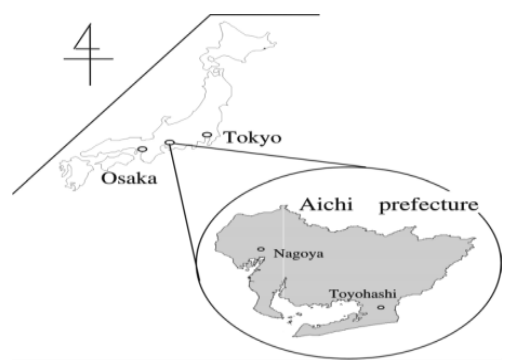

Figure 1: Location of Toyohashi City in Japan [12].

\subsection{Methodology}

The underlying approach of this study is the CGE model. In this study we have applied a CGE model similar to our previous study [5] to investigate the economic impact of EVS in Toyohashi City, Japan. In constructing the model, the authors referred to the literature of Miyata and Shibusawa [2], Shoven and Whally [3], and Shibusawa and Sugawara [4]. In our model the economic agents are households, the firms in 38 industries, the government and the external sector. A total of 40 markets are considered comprising 38 commodity markets (see Table 1), one labour market and one capital market. These are assumed to be perfectly competitive and in equilibrium in 2005. 


\begin{tabular}{|c|c|}
\hline industries & industries \\
\hline 1. agriculture, forestry \& fishery & 20. aircraft \\
\hline 2. mining & 21. other transportation equipment \\
\hline 3. food processing & 22. precision equipment \\
\hline 4. textile product & 23. other manufactured \\
\hline 5. pulp, paper \& wooden product & 24. construction \\
\hline 6. chemical & 25. electric power \\
\hline 7. coal \& petroleum product & 26. solar power \\
\hline 8. plastic product & 27. gas supply \\
\hline 9. ceramic & 28. heat \\
\hline 10. stone \& clay product & 29. cogeneration \\
\hline 11. iron \& steel product & 30. water supply \& sanitary servive \\
\hline 12. non-ferrous metal & 31. commerce \\
\hline 13. metal product & 32. financial \& insuance service \\
\hline 14. general machinery & 33. reale state \\
\hline 15. electrical machinery & 34. GVs transhipment \\
\hline 16. information \& communication electronic equipments & 35. Evs transhipment \\
\hline 17. electronic component & 36. other transhipment \\
\hline 18. gasoline vehicles (GVs) & 37. telecommunication $\&$ broadcasting \\
\hline 19. electric vehicles (EVs) & 38. service \\
\hline
\end{tabular}

\section{Assumptions of the Model}

\subsection{Main Assumptions}

The main assumptions made in our model are as follows:

(1) The 2005 Toyohashi City's economy is examined. The economic agents are households, the firms in 38 industries, the government and the external sector.

(2) 40 markets are considered comprising 38 commodity markets, one labour market and one capital market. These are assumed to be perfectly competitive and in equilibrium in 2005 .

\subsection{Behaviour of industries}

In industries, intermediate input, labour and capital are inputted to produce goods. Industries have the Cobb-Douglas technology with respect to intermediate input and labour and capital inputs, and Leontief technology with value added inputs (see Figure 2). Constant returns to scale are assumed in the technology, in which the cost minimization problem can be written as follows:

$$
\min \sum_{i=1}^{38} p_{i} x_{i j}+\left(1+t p_{j}\right)\left(w L_{j}+r K_{j}\right)(j=1, \ldots, 38)
$$

with respect to $x_{i j}, L_{j}$ and $K_{j}$

subject to

$$
\begin{aligned}
& X_{j}= \min \left[\frac{1}{a_{10 j}} f_{j}\left(L_{j}, K_{j}\right), \frac{x_{1 j}}{a_{1 j}}, \ldots, \frac{x_{i j}^{\prime}}{a_{i j}^{\prime}}, \ldots, \frac{x_{38 j}}{a_{38 j}}\right] \\
& x_{18 j}^{\prime}= x_{18 j}^{\alpha_{18 j}} x_{19 j}^{\alpha_{19 j}} \quad\left(\alpha_{18 j}+\alpha_{19 j}=1\right) \\
& x_{25 j}^{\prime}= x_{25 j}^{\alpha_{25 j}} x_{26 j}^{\alpha_{26 j}} \quad\left(\alpha_{25 j}+\alpha_{26 j}=1\right) \\
& x_{27 j}^{\prime}= x_{27 j}^{\alpha_{27 j}} x_{28 j}^{\alpha_{28 j}} x_{29 j}^{\alpha_{29 j}} \quad\left(\alpha_{27 j}+\alpha_{28 j}+\alpha_{29 j}=1\right) \\
& x_{34 j}^{\prime}= x_{34 j}^{\alpha_{34 j}} x_{35 j}^{\alpha_{35 j}} x_{36 j}^{\alpha_{36 j}} \quad\left(\alpha_{34 j}+\alpha_{35 j}+\alpha_{36 j}=1\right) \\
& f_{j}\left(L_{j}, K_{j}\right) \equiv A_{1 j} L_{j}^{a_{j}} K_{j}^{\left(1-a_{j}\right)}
\end{aligned}
$$

where

$p_{i}:$ price of commodity $I$

$x_{i j}$ : intermediate input of industry $i$ 's product in industry $j$

$t p_{j}$ : net indirect tax rate imposed on industry $j$ 's product (indirect tax rate - subsidy rate)

$w$ : wage rate

$r$ : capital return rate

$L_{j}$ : labor input in industry $j$

$K_{j}$ : capital input in industry $j$

$X_{j}$ : output in industry $j$

$a_{0 j}$ : value added rate in industry $j$ 
$a_{i j}$ : share parameter on intermediate input $x_{i j}$

$A_{i j}, \alpha_{i j}:$ technical parameters in industry $j$

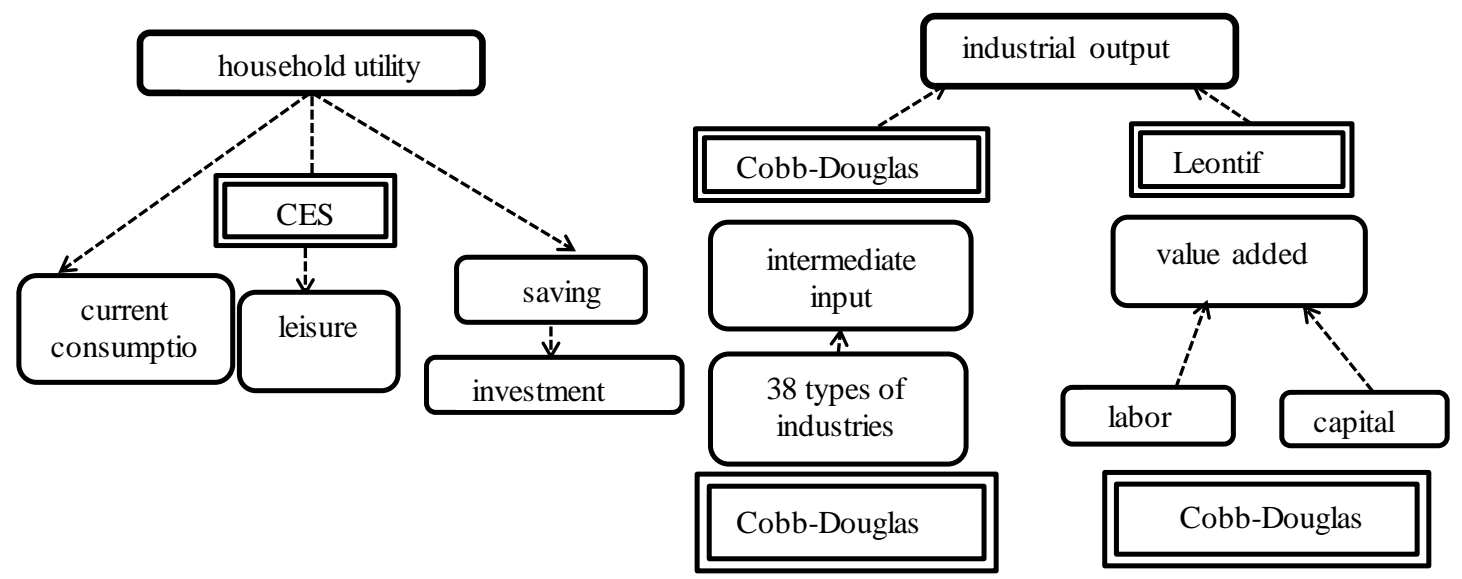

Figure 2: Hierarchical structure of the CGE model

Conditional demands for intermediate goods, labour, and capital in production process are as follows:

$$
\begin{aligned}
& x_{i j}=a_{i j} X_{j} \\
& x_{18 j}=\frac{\alpha_{18 j}}{p_{18}}\left[\frac{p_{18}}{\alpha_{18 j}}\right]^{\alpha_{18 j}}\left[\frac{p_{19}}{\alpha_{19 j}}\right]^{\alpha_{19 j}} a_{18 j}^{\prime} X_{j} \\
& x_{19 j}=\frac{\alpha_{19 j}}{p_{19}}\left[\frac{p_{18}}{\alpha_{18 j}}\right]^{\alpha_{18 j}}\left[\frac{p_{19}}{\alpha_{19 j}}\right]^{\alpha_{19 j}} a_{18 j}^{\prime} X_{j} \\
& x_{25 j}=\frac{\alpha_{25 j}}{p_{25}}\left[\frac{p_{25}}{\alpha_{25 j}}\right]^{\alpha_{25 j}}\left[\frac{p_{26}}{\alpha_{26 j}}\right]^{\alpha_{26 j}} a_{25 j}^{\prime} X_{j} \\
& x_{26 j}=\frac{\alpha_{26 j}}{p_{26}}\left[\frac{p_{25}}{\alpha_{25 j}}\right]^{\alpha_{25 j}}\left[\frac{p_{26}}{\alpha_{26 j}}\right]^{\alpha_{26 j}} a_{25 j}^{\prime} X_{j} \\
& x_{27 j}=\frac{\alpha_{27 j}}{p_{27}}\left[\frac{p_{27}}{\alpha_{27 j}}\right]^{\alpha_{27 j}}\left[\frac{p_{28}}{\alpha_{28 j}}\right]^{\alpha_{28 j}}\left[\frac{p_{29}}{\alpha_{29 j}}\right]^{\alpha_{29 j}} a_{27 j}^{\prime} X_{j} \\
& x_{28 j}=\frac{\alpha_{28 j}}{p_{28}}\left[\frac{p_{27}}{\alpha_{27 j}}\right]^{\alpha_{27 j}}\left[\frac{p_{28}}{\alpha_{28 j}}\right]^{\alpha_{28 j}}\left[\frac{p_{29}}{\alpha_{29 j}}\right]^{\alpha_{29 j}} a_{27 j}^{\prime} X_{j} \\
& x_{29 j}=\frac{\alpha_{29 j}}{p_{29}}\left[\frac{p_{27}}{\alpha_{27 j}}\right]^{\alpha_{27 j}}\left[\frac{p_{28}}{\alpha_{28 j}}\right]^{\alpha_{28 j}}\left[\frac{p_{29}}{\alpha_{29 j}}\right]^{\alpha_{29 j}} a_{27 j}^{\prime} X_{j} \\
& x_{34 j}=\frac{\alpha_{34 j}}{p_{34}}\left[\frac{p_{34}}{\alpha_{34 j}}\right]^{\alpha_{34 j}}\left[\frac{p_{35}}{\alpha_{35 j}}\right]^{\alpha_{35 j}}\left[\frac{p_{36}}{\alpha_{36 j}}\right]^{\alpha_{35 j}} a_{34 j}^{\prime} X_{j} \\
& x_{35 j}=\frac{\alpha_{35 j}}{p_{35}}\left[\frac{p_{34}}{\alpha_{34 j}}\right]^{\alpha_{34 j}}\left[\frac{p_{35}}{\alpha_{35 j}}\right]^{\alpha_{35 j}}\left[\frac{p_{36}}{\alpha_{36 j}}\right]^{\alpha_{35 j}} a_{34 j}^{\prime} X_{j}
\end{aligned}
$$




$$
\begin{aligned}
x_{36 j} & =\frac{\alpha_{36 j}}{p_{36}}\left[\frac{p_{34}}{\alpha_{34 j}}\right]^{\alpha_{34 j}}\left[\frac{p_{35}}{\alpha_{35 j}}\right]^{\alpha_{35 j}}\left[\frac{p_{36}}{\alpha_{36 j}}\right]^{\alpha_{35 j}} a_{34 j}^{\prime} X_{j} \\
L D_{j} & =\left[\frac{\left(1-\alpha_{j}\right) r}{\alpha_{j} w}\right]^{\alpha_{j}} \frac{a_{0 j} X_{j}}{A_{j}} \\
K D_{j} & =\left[\frac{a_{j} w}{\left(1-a_{j}\right) r}\right]^{\left(1-a_{j}\right)} \frac{a_{0 j} X_{j}}{A_{j}}
\end{aligned}
$$

$L D_{j}$ : conditional demand for labour in industry $j, K D_{j}$ : conditional capital demand in industry $j$ Zero profit condition is realized in the industries under a perfect competition.

profit $=p_{j} X_{j}-\sum_{i=1}^{38} p_{i} x_{i j}-\left(1+t p_{j}\right)\left[w \cdot L D_{j}+r \cdot K D_{j}\right]=0$

\subsection{Behaviour of households}

The households in Toyohashi City are assumed to be homogeneous with the fixed number of households. Thus, one can consider that the households share an aggregate single utility function. To explain the household behaviour, first, derivation of future good is described here. The future good implies the future consumption which is derived from the household saving, however, the saving formulates capital investment. Therefore, capital good can be regarded as saving good.

Investment is made by using produced goods, and let their portions in investment be denoted by $b_{i}$ $P_{I}=\sum_{i=1}^{38} b_{i} p_{i}$. Denoting the price of investment good by $p_{I}$ is realized. Then, the price of investment good is expressed as, $p_{I} I=\sum_{i=1}^{38} p_{i} I_{i}$. This can be regarded as the price of saving good $p_{s}$.

$$
r_{s}=(1-t y)\left(1-k_{o}\right)\left(1-k_{r}\right) r \delta / p_{s}
$$

where

ty: direct tax rate imposed on households

$k_{o}$ : rate of transfer of property income to the external sector

$k_{r}$ : capital depreciation rate

$\delta$ : ratio of capital stock measured by physical commodity unit to that by capital service unit.

Then, the derivation of demands for composite consumption and leisure time from the current good $G$ is described. The current good $G$ is a composite of consumption and leisure time, and $G$ is obtained from the following optimization problem:

$$
\max _{C, F} G \equiv\left\{\beta^{1 / v_{2}} C^{\left(v_{2}-1\right) / v_{1}}+(1-\beta)^{1 / v_{1}} F\right\}^{v_{2} /\left(v_{2}-1\right)}
$$

which is subjected to

$p \cdot C+(1-t y)\left(1-l_{o}\right) w \cdot F=(1-t y) F I-T r H O-S H$

By solving this utility maximization problem, the demand functions for composite consumption, leisure time and labour supply are obtained.

$$
\begin{aligned}
& C=\frac{\beta[(1-t y) F I-\operatorname{TrHO}-S H]}{p^{v_{2}} \cdot \Omega} \\
& F=\frac{(1-\beta)[(1-t y) F I-\operatorname{Tr} H O-S H]}{\left[(1-t y)\left(1-l_{o}\right) w\right]^{v_{2}} \cdot \Omega} \\
& L S=E-F \\
& \Omega=\beta p^{\left(1-v_{2}\right)}+(1-\beta)\left[(1-t y)\left(1-l_{o}\right) w\right]^{\left(1-v_{2}\right)} \\
& \text { where }
\end{aligned}
$$

$L S$ : household labour supply

$\beta$ : share parameter

$v_{2}$ : elasticity of substitution between composite consumption and leisure time

$C$ : composite consumption

$F$ : leisure time

$p$ : price of composite consumption good

$S H$ : household nominal saving $\left(=P_{S} \cdot S\right)$

By substituting the composite consumption (25) and leisure time (26) into (23), the price index of the present good is derived as follows: 
$p_{G}=\left\{\beta p^{1-v_{2}}+(1-\beta)\left[(1-t y)\left(1-l_{o}\right) w\right]^{1-v_{2}}\right\}^{1 /\left(v_{2}-1\right)}$

Moreover, composite consumption good is disaggregated into produce goods through the maximization of a Cobb-Douglas sub-utility function given the household income and leisure time.

$\max C \equiv \prod_{i=1}^{38} C_{i}^{\gamma_{i}} \quad\left(\sum_{i=1}^{38} \gamma_{i}=1\right)$

subject to

$\sum_{i=1}^{38} p_{i} \cdot C_{i}=(1-t y) Y-T r H O-S H$

where

$C_{i}$ : household consumption good produced by industry $I$

$p_{i}$ : price of good $I$

$Y$ : household income

$\left(=\left(1-l_{o}\right) w \cdot L S+L I+\left(1-k_{o}\right)\left(1-k_{r}\right) r \cdot K S+K I+\operatorname{Tr} G H+\operatorname{Tr} O H\right)$

From this optimization problem, consumption good $i$ is derived.

$C_{i}=\frac{\gamma_{i}}{p_{i}}[(1-t y) Y-\operatorname{TrHO}-S H](i=1, \cdots, 38)$

The price of composite consumption is calculated as follows:

$$
p=\prod_{i=1}^{38}\left[\frac{p_{i}}{\gamma_{i}}\right]^{\gamma_{i}}
$$

\subsection{The government}

The government sector in this study consists of the national and local governmental activities in Toyohashi City. Thus, the concept of the government corresponds to the definition of SNA framework. The government obtains its income from direct and net indirect taxes of Toyohashi City, and current transfers from the external sector, and then it expends the income on government consumption, current transfers to households, and current transfers to the external sector. The difference between income and expenditures is saved. Nominal consumption expenditures on commodities/services are assumed to be proportional to the government revenue with constant sectorial share. These are expressed as the following balance of payments:

$$
\sum_{i=1}^{38} p_{i} \cdot C G_{i}+\operatorname{Tr} G H+\operatorname{Tr} G O+S G=t y \cdot Y+\sum_{i=1}^{38} t p_{i}\left(w \cdot L D_{i}+r \cdot K D_{i}\right)+\operatorname{Tr} O G
$$

where

$C G_{i}$ : government consumption expenditures on commodity $I$

$\operatorname{TrGH}$ : current transfers to households

$\operatorname{TrGO}$ : current transfers to the external sector

$S G$ : government savings

$\operatorname{Tr} O G$ : current transfers from the external sector

\subsection{The external sector}

The external sector gains its income from Toyohashi City's imports, current transfers from the government, labour income transfers and property income transfers. Then, it expands the income on exports and transfer of Toyohashi, current transfers to households and the government, labour (employees to Toyohashi) and property income transfers. These are also described as the following balance of payment:

$$
\sum_{i=1}^{38} p_{i} \cdot E X_{i}+\operatorname{TrOH}+\operatorname{TrOG}+\mathrm{KI}+\mathrm{LI}+\mathrm{SO}=\sum_{i=1}^{38} p_{i} \cdot E M_{i}+\operatorname{TrHO}+\operatorname{Tr} G \mathrm{O}+\mathrm{KIO}+\mathrm{LIO}
$$

where

$E X_{i}$ : export of commodity $I$,

$E M_{i}$ : import of commodity $I$,

$S O$ : savings of the external sector (= national current surplus)

$L I O$ : labour income transfers to the external sector $\left(=l_{o} \cdot w \cdot L S\right)$

$K I O:$ property income transfers to the external sector $\left(=k_{0} \cdot r \cdot K S\right)$

\subsection{Balance of investment and savings}

Household, government, the area department's savings, and the total consumption of fixed capital determine the total investment. 
$\sum_{i=1}^{38} p_{i} \cdot I_{i}=S H+S G+S O+\sum_{i=1}^{38} D R_{i}$

where

$I_{i}$ : demand for commodity $i$ by other investments,

$D R_{i}$ : consumption of fixed capital amount of industry $i$

\subsection{Prices of commodity}

Cost consists of the following, which is derived from the zero profit condition of the industry:

$p_{j} X_{j}=\sum_{i=1}^{38} p_{i} x_{i j}+\left(1+t p_{j}\right)\left[w \cdot L D_{j}+r \cdot K D_{j}\right]$

Given a wage and a capital return rate, we can formally calculate the commodity prices as follows:

$P=\left(I-A^{\prime}\right)^{-1}\left[\left(1+t p_{j}\right)\left(w \cdot l d_{j}+r \cdot k d_{j}\right)\right]$

where

$P$ : vector of commodity prices,

$A^{\prime}$ : transposed matrix of industries' input coefficients,

$[\cdot]$ : column vector whose elements are in parentheses $l d_{j} \equiv L D_{j} / X_{j}$ and $k d_{j} \equiv K D_{j} / X_{j}$

\subsection{Derivation of equilibrium}

The equilibrium condition in the model can be summarized as follows:

Commodity Market

$\left[\begin{array}{c}X_{1} \\ \vdots \\ X_{31}\end{array}\right]=\left[\begin{array}{ccc}a_{11} & \cdots & a_{131} \\ \vdots & \ddots & \vdots \\ a_{311} & \cdots & a_{313}\end{array}\right]\left[\begin{array}{c}X_{1} \\ \vdots \\ X_{31}\end{array}\right]+\left[\begin{array}{c}C_{1} \\ \vdots \\ C_{31}\end{array}\right]+\left[\begin{array}{c}C G_{1} \\ \vdots \\ C G_{31}\end{array}\right]+\left[\begin{array}{c}I_{1} \\ \vdots \\ I_{31}\end{array}\right]+\left[\begin{array}{c}E X_{1} \\ \vdots \\ E X_{31}\end{array}\right]+\left[\begin{array}{c}E M_{I} \\ \vdots \\ E M_{31}\end{array}\right.$

Labour Market

$L S=\sum_{j=1}^{38} L D_{j}$

Capital Market

$K S=\sum_{j=1}^{38} K D_{j}$

\section{Simulation cases and simulation results}

4.1 Simulation cases

Two cases are simulated in this study as follows:

(1) Case one (business as usual). The simulation of this part has done by simply calculating the input- output (I-O) table of Toyohashi City, Japan.

(2) Case two (introduces $20 \%$ subsidy to the industries including EVs manufacturing and transhipment, solar power, cogeneration, and other transport).

\subsection{Simulation results}

In this section, we present the simulation results by referring to some important economic variables, as explained in the following.

\subsubsection{Industrial outputs}

The changes in industrial outputs are shown in Figures 3 and 4. Industries with large production are found in service, commerce, GVs manufacturing, and construction sectors. It is seen that industries related to automobile are large in Toyohashi City because Toyota Motor Company (one of the world's largest automobile manufactures by production) is located in this area. The number of new industries of which the growth is expected this time is few. In particular, a large increase rate is found in industries like solar energy $(1.42 \%)$, cogeneration $(0.85 \%)$, EVs manufacturing and transhipment $(0.46 \%)$ and $(0.80 \%)$, respectively, other transhipment $(0.73 \%)$, and non-ferrous metal $(0.54 \%)$. The balance of the growth between industrial changes depends on the subsidy policy. The reason behind large increase rate in non-ferrous metal corresponds to the demand for producing batteries used in EVs. Because non-ferrous metal is necessary for producing batteries used in EVs. Thus, the rise of non-ferrous metal production is indirectly influenced by the subsidy policy on EVs production. Decreasing tendency is found in some industries, for instance, oil, coal product ($0.30 \%)$, mining $(-0.06 \%)$, heat supply $(-0.39 \%)$, and the GVs transhipment $(-0.10 \%)$. And this situation is considered as a positive factor of this study. The reason behind the large decrease of oil, 
Economic Impacts of an Electric Vehicle Society in Toyohashi City, Japan-A CGE

coal product industry is according to an increase in share of EVs, solar energy, and cogeneration, moreover, falling trend in mining is related to reduce of oil, coal production. And a decline in the heat supply industry is found because of growing share of cogeneration. The total industrial output increase $0.07 \%$.

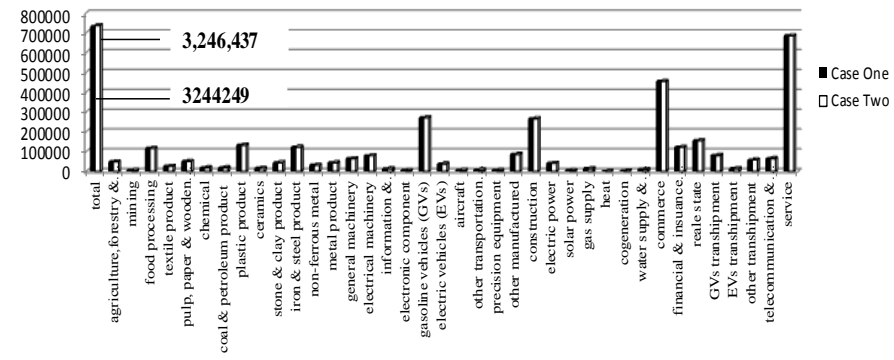

Figure 3. Industrial output.

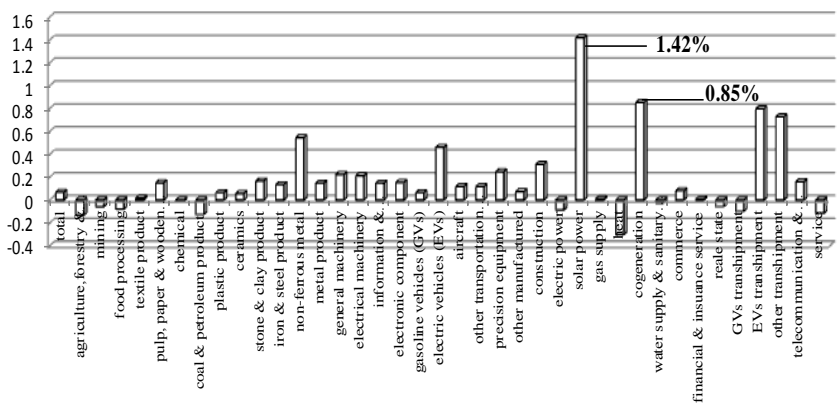

Figure 4. Change rate of industrial output.

\subsubsection{City's GDP}

The city's GDP is defined as the gross value added according to the industrial output. Toyohashi City's total real GDP grows by $0.8 \%$. City GDP depends on industrial output shown in Figures 5 and 6 . In general net indirect tax decreases by subsidy policy, and industries with a high decrease rates are found in photovoltaic generation (-1.78\%), EVs manufacturing $(-0.91 \%)$, cogeneration $(-0.50 \%)$, EVs transhipment $(-0.88 \%)$, other transhipment $(-1.01 \%)$, and heat supply industry $(-0.30 \%)$ where subsidies are introduced. However an increasing trend is found in industries like non-ferrous metal $(0.54 \%)$ and construction $(0.31 \%)$ oppositely.

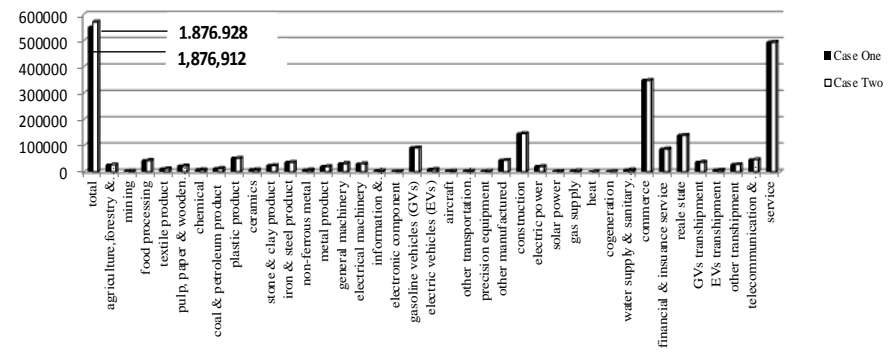

Figure 5: City's GDP.

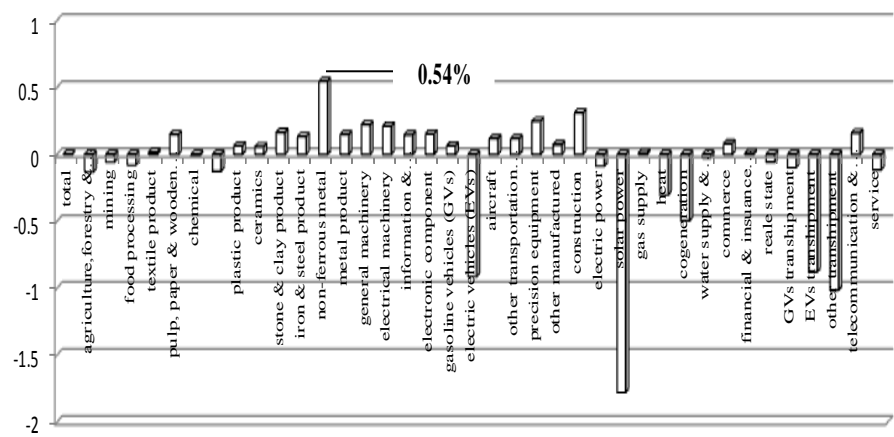


Figure 6: The change rate of city's GDP

\subsubsection{Labour demand}

Looking at the changes in labour demand by sector in Figures 7 and 8, it can be seen that the changes in labour demand in industry corresponds to the expense of the subsidy policy. That is labour demand has risen in industries which an additional subsidies are expended. A large increasing trend in labour demand is found in solar energy $(5.84 \%)$, cogeneration $(4.50 \%)$, other transhipment $(2.44 \%)$, and EVs manufacturing and transhipment $(1.74 \%)$ and $(1.08 \%)$ respectively. The total labour demand increases $(0.08 \%)$. Taking into account the current serious situation of job opportunity and increase in labour demand may be interpreted as a positive fact. However, this reduces leisure time implying that the household utility would show a decrease in some cases

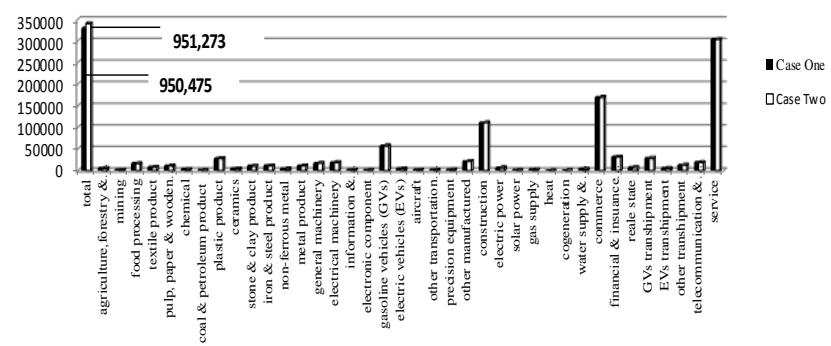

Figure 7: Labour demand in industries.

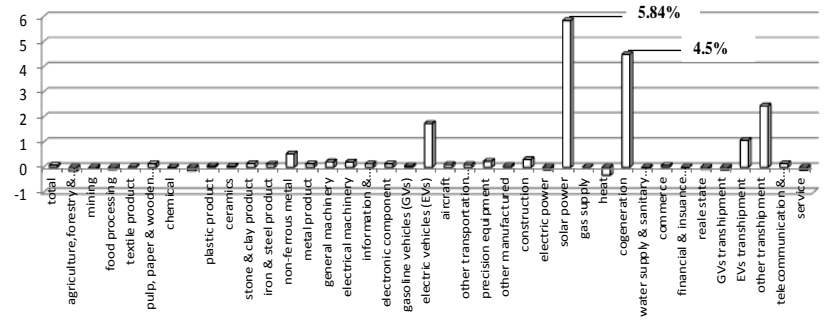

Figure 8: The change rate of labour demand in industries.

\subsubsection{Capital demand}

Since the total capital endowment by household is fixed in this model, therefore, the total demand for capital does not change either. Looking at the changes in capital demand by industry as, shown in Figures 9 and 10, the manner of changes is considerable different from the labour demand in industries. It is natural that after introducing the new production, the demand for capital tends to increase resulting in an increase in the capital return rate. To avoid this situation we introduces $20 \%$ subsidies, as a result decreasing trend of capital demand is found in all industries to which an additional subsidies have been expended, such as other transhipment $(-1.02 \%)$, EVs manufacturing and transhipment $(-0.91 \%)$ and $(-0.86 \%)$, respectively, cogeneration $(-0.50 \%)$, heat supply ($0.30 \%)$. However a large decrease rate of capital demand is seen in solar energy $(-1.80 \%)$. Therefore, the substitution in factor of production from capital to labour will be transformed in these industries. On the other hand, an increase in capital demand is seen in non-ferrous metal industry $(0.56 \%)$ and construction $(0.33 \%)$ which correspondence to an increase the amount of production. 


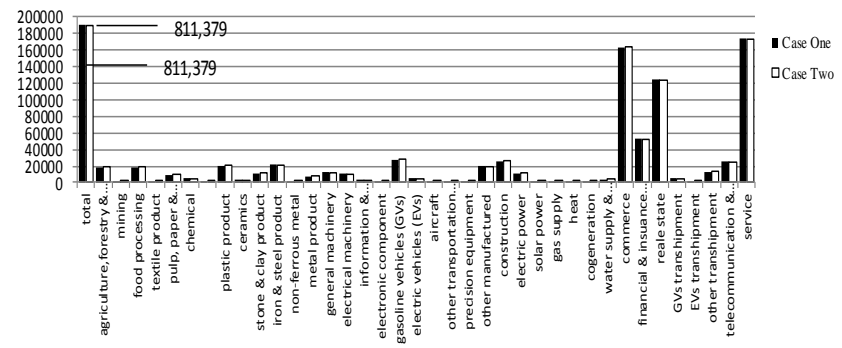

Figure 9: Capital demand

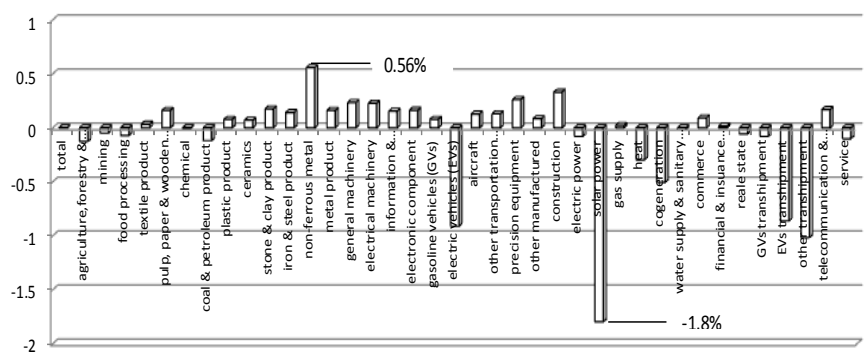

Figure 10: The change rate of capital demand

\subsubsection{Commodity prices}

The commodity prices are determined by the price of factor of production. Since the numerare is set up as labour in this model, the capital return rate is adjusted for equilibrated the market. Because the benchmark data set doesn't equilibrate in this model, all prices do not become 1 in Case one though the capital return rate is determined so as to equilibrate the total capital supply and demand. In Case two, with an additional subsidy the price of industry decreases. That is why, observing Figure 11 and Figure 12, the price of solar energy $(-1.53 \%)$, other transhipment ($1.09 \%)$, EVs manufacturing and transhipment $(-0.42 \%)$ and $(-1.00 \%)$, cogeneration $(-0.32 \%)$ decreases greatly. The price of other transhipment decrease significantly, however the price of GVs transhipment decrease a little $(-0.11 \%)$. The decreasing trend of all the commodity prices are found due to introduce subsidies in some industries, thus the consumer price index is fall $(0.05 \%)$.

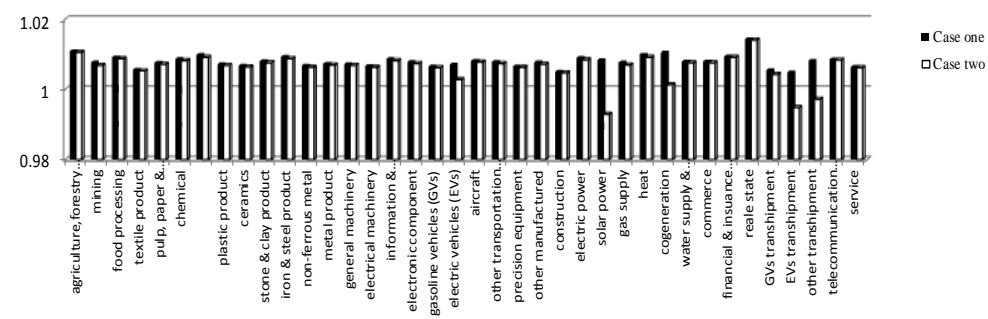

Figure 11: Prices of commodity

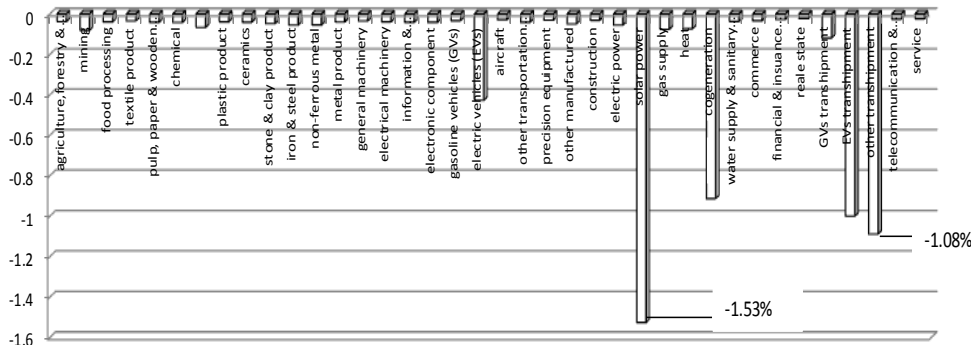

Figure 12: The change rate of commodity prices. 


\subsubsection{Other variables}

Let us look at Figures 13 and 14 to see the changes in other variables. Large increase rates are found in the total investment $(0.29 \%)$, EVs purchase $(0.33 \%)$, and labour supply $(0.08 \%)$. The increase in the labour supply corresponds to a growth in the labour demand associated with the increase in the gross value added rate. Besides, decreasing trend is found in some variables, especially in household income. A decrease in household income relates to reduce of capital return rate and that stage production factor and savings will be decreased. Moreover, decreasing trend is also found in net indirect tax, and in all sector of government, such as annual revenue, government savings. The consumer prices decreases plus there was an income effect, as a result decrease household income and leisure time. Toyohashi City's economy shows a direction where the primary consumption is surely decreased; it is considerably as a positive factor and key issue that is different from the present lifestyle.

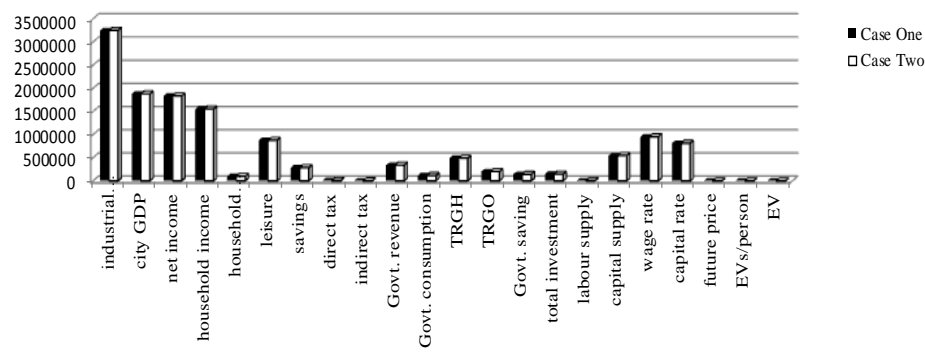

Figure 13: Other variables

Note:

$T R G H$ : current transfer from the government to households

$T R G O$ : current transfers from the government to the rest of the world

$E V$ : equivalent variation

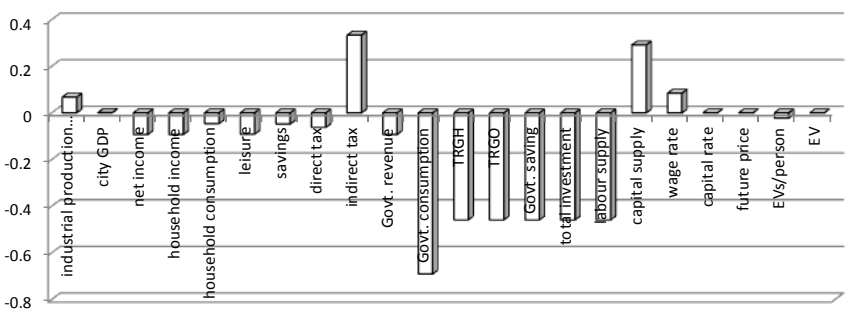

Figure 14: The change rate of other variables.

\section{Concluding Remarks}

In this article we have applied a CGE model to evaluate the possibility and economic impacts of an EVS taking Toyohashi City, Japan as a study region. By employing the CGE model, the two numerical simulations have been implemented. From the simulation results, some interesting conclusions have been made.

The results demonstrate that after introducing subsidies, total industrial output increases $0.07 \%$. A large increase rate is found in industries like solar $(1.42 \%)$, cogeneration $(0.85 \%)$, EVs manufacturing $(0.46 \%)$, transhipment and $(0.80 \%)$, other transhipment $(0.73 \%)$, and non-ferrous metal $(0.54 \%)$. However, conversely decreasing tendency is seen in oil, coal product $(-0.30 \%)$, mining $(-0.06 \%)$, heat supply $(-0.39 \%)$, and the GVs transhipment $(-0.10 \%)$. The reason behind the large decrease of oil and coal products is according to an increase the share of EVs, solar, and cogeneration, and a decrease in mining is relates to a decline of oil and the coal product. Moreover, a decreasing trend in the heat supply industry is found because of increasing share of cogeneration.

A total industrial output increase in $0.07 \%$, as the city GDP depends on industrial output, thus the total real GDP also grows by $0.8 \%$ in Toyohashi City. Besides, a total labour demand increase $0.08 \%$, however a large increasing trend in labour demand is found in solar energy (5.84\%), cogeneration (4.50\%), other transhipment $(2.44 \%)$, and EVs manufacturing and transhipment $(1.74 \%)$ and $(1.08 \%)$ respectively. Taking into account the current serious situation of job opportunity an increase in labour demand may be interpreted as a positive fact. 
Economic Impacts of an Electric Vehicle Society in Toyohashi City, Japan-A CGE

Moreover, all the commodity prices decreases though in industries where subsidies are presented prices shrink appreciably. For example, solar energy $(-1.53 \%)$, other transhipment ($1.09 \%)$, EVs manufacturing and transhipment $(-0.42 \%)$ and $(-1.00 \%)$, cogeneration $(-0.32 \%)$ decreases greatly.

Hence, Toyohashi City's economy shows a direction where the demand for conventional vehicles and energy are decreased, conversely, the demand for EVs and renewable energy are increased that displays different lifestyles from the current. In this study therefore it is clear that model shift occurs to EVS. For all these reasons, as a conclusion of the study, it is authors' opinion that presenting $20 \%$ subsidies to EVs manufacturing and transhipment, solar, cogeneration, and other transhipment can really represent a realistic alternative society to EVS, both in terms of economic development and $\mathrm{CO}_{2}$ emissions reduction. Thus we suggest for promotion of new industrial structure to introduce an EVS in Toyohashi city, Japan. The proposed model even can be expanded to the other cities in Japan and other countries in the world which are similar to this area.

\section{Acknowledgements}

The authors' are grateful to Amano Institute of Technology for offering the financial supports of this study.

\section{References}

[1] J.K. Valerie, Prospects for plug-in hybrid electric vehicles in the United states and Japan: A General Equilibrium Analysis, Elsevier, Transportation Research, Part A 44, 2010, pp.620-641.

[2] Y. Miyata, H. Shibusawa, Does the increase in the Population Prevent a Sustainable Growth of an Environmentally Friendly City?-A comparison of case of Decreasing and Increasing Population of Obihiro Metropolitan Area, Japan by an Intertemporal CGE Modeling Approach, Interdisciplinary Information sciences, Vol. 14. No.1, pp. 1 24.

[3] J. B. Shoven and J. Whalley, Applying general equilibrium, Cambridge survey of Economic Literature, 2007, Cambridge University Press.

[4] H. Shibusawa and T. Sugawara, Evaluation the Economic Impacts of the Production of New Generation Automobiles with Technological Innovations. Studies in Regional Science, Vol 41, No.1, 2011, pp. 127-146.

[5 S. Khanam and Y. Miyata (accepted), New Industrial Structure Coping the Economic Impacts of Shifting Production to Battery -based Electric vehicle in Toyohashi City in Japan-A CGE Modeling Approach-, RSI Journal, Vol IV, No 3, Special Issue, December, 2012.

[6] IEA (International Energy Agency), 2006, World Energy Outlook, Paris, France. [8] MOE (Ministry of Environment, Japan), 2007, National Greenhouse Gas Inventory Report Japan.

[7] MOE (Ministry of Environment, Japan), 2007, National Greenhouse Gas Inventory Report of Japan.

[8] MOE (Ministry of Environment, Japan), 1997, Kankyo Hakusho (Environmental white paper of Japan), 1997. [in Japanese].

[9] GGIOJ (Greenhouse Gas Inventory Office of Japan), (2008), "National GHGs Inventory Report of Japan", <http://wwwgio.nies.go.jp/aboutghg/nir/nir-e.html>

[10] Toyohashi City Statistics (2011): http://www.citypopulation.de/php/japan-aichi.php?cityid=23201

[11] Toyohashi City Web page (2011): http://www.city.toyohashi.aichi.jp/en/index.html

[12] Naohiro, G., et al., (2005), "Environmental Management System Based on Material Flow Analysis to Establish andMaintainEcoTown",J.Ind.Eng.Chem.,Vol. 11, No. 6. pp. 818-825. http://www.cheric.org/PDF/JIEC/IE11/IE116-0818.pdf> 